\title{
Vascular rings: a rare cause of common respiratory symptoms
}

\author{
DAH Bakker ${ }^{1}$, RMF Berger ${ }^{2}$, M Witsenburg $^{2}$ and AJJC Bogers ${ }^{3}$ \\ Department of Paediatrics ${ }^{1}$, Division of Paediatric Cardiology ${ }^{2}$, Department of Cardio-Thoracic Surgery ${ }^{3}$, Sophia Children's Hospital/ \\ University Hospital Rotterdam, The Netherlands
}

\begin{abstract}
Bakker DAH, Berger RMF, Witsenburg M, Bogers AJJC. Vascular rings: a rare cause of common respiratory symptoms. Acta Pædiatr 1999; 88: 947-52. Stockholm. ISSN 0803-5253

Upper airway symptoms or dysphagia may be caused by vascular anomalies, forming a ring around the trachea, oesophagus or both. To analyse the clinical presentation, use of various diagnostic techniques, treatment and follow-up we carried out a retrospective study of 38 children who had been diagnosed with a vascular ring between 1981 and 1996 . We found $74 \%$ of the vascular rings to be symptomatic, with inspiratory stridor and wheezing as the main complaints. The delay between the onset of symptoms and diagnosis of a vascular ring in patients without associated anomalies ranged from 1 to 84 mo. Associated anomalies were found in $53 \%$ of cases and $80 \%$ of these anomalies consisted of associated cardiovascular malformations. Oesophagography proved to be a valuable diagnostic technique when a vascular ring was suspected. Echocardiography appeared to be of little value for the diagnosis of a vascular ring, but was essential to exclude associated cardiovascular malformations. Although angiography has always been considered to be the gold standard in the determination of the exact anatomy of vascular rings, increasing evidence is available that CT scan or MRI may replace this role. Mortality was related to co-existent tracheal deformities in 5/6 cases. Of the remaining, preoperatively symptomatic patients, relief of symptoms was achieved immediately after surgery in $43 \%$ and within $4 \mathrm{y}$ after surgery in $57 \%$. Prolonged and recurrent respiratory complaints or dysphagia in infancy or childhood should alert the paediatrician to the possibility of a vascular ring. $\square$ Associated cardiovascular malformations, childhood, clinical presentation, diagnostic techniques, follow-up, surgical management, vascular ring
\end{abstract}

RMF Berger, Division of Paediatric Cardiology, Sophia Children's Hospital/University Hospital Rotterdam, Dr. Molewaterplein 60, 3015 GJ, Rotterdam, The Netherlands (Tel. +31 104636264 , fax. +31104636801$)$

Upper airway or digestive tract symptoms are common in childhood. Rarely, these symptoms are due to tracheal or oesophageal compression by congenital anomalies of the aortic arch system. Such abnormalities are the result of abnormal regression of parts of the branchial arch system during foetal life and may result in complete or incomplete encirclement of the trachea, oesophagus or both. In 1945, Gross introduced the term "vascular ring" to describe these mediastinal vascular anomalies and reported a successful operation on a double aortic arch. (1) During the years that followed, aortic arch anomalies became a recognized clinical entity. In 1948, Edwards did the first classification of vascular rings. (2) Vascular rings were classified according to embryological, pathological and radiographic criteria by Klinkhamer and Stewart, $(3,4)$; this classification is still in use.

Patients with vascular rings may present with severe symptoms of respiratory distress directly after birth, for instance in the case of a pulmonary sling with tracheal malacia or, in contrast, they may be asymptomatic for life. Most children with vascular rings, however, present with non-specific symptoms, such as dyspnoea, cough, inspiratory stridor, recurrent respiratory tract infections (RTI) or dysphagia. Due to the high prevalence and non-specific nature of these symptoms, on the one hand, and the low prevalence of vascular rings of approximately $1 \%(5,6)$, leading to unfamiliarity with the condition of the general paediatrician, on the other hand, the diagnosis of a vascular ring may be easily overlooked in these patients. Although oesophagography has been reported as a reliable first diagnostic procedure, consensus on the optimal diagnostic workup in case of a suspected vascular ring is not widely recognized (7-11).

In this respect we report on the presenting symptoms, diagnostic procedures and follow-up of 38 children diagnosed with a vascular ring. The aims of this study were to describe the clinical presentation of infants and children with vascular rings, the diagnostic value of different imaging techniques and the implications of surgical management and follow-up. 

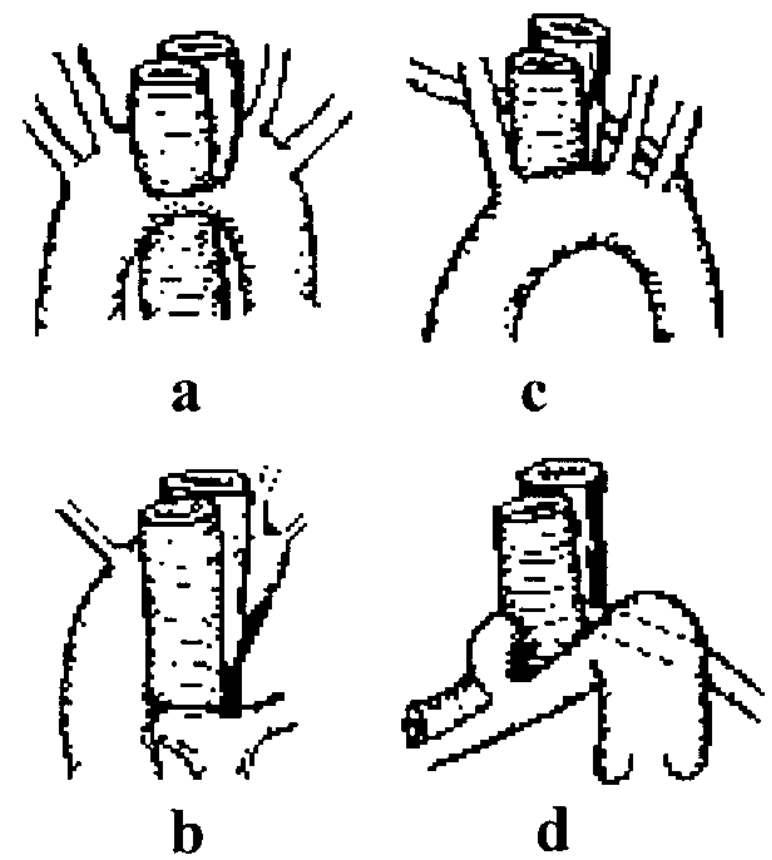

Fig. 1. (a) Double aortic arch, (b) right aortic arch with persistent left ligament, (c) aberrant right subclavian artery, (d) pulmonary sling.

\section{Patients and methods}

Clinical records of 38 patients, diagnosed with a vascular ring between February 1981 and June 1996, were examined retrospectively. Presenting symptoms were registered and included a history of wheezing, inspiratory stridor, dyspnoea, cough, recurrent RTI and dysphagia. Diagnostic procedures performed were chest X-ray, echocardiography, oesophagography, biplane angiography, bronchoscopy and CT scan. Associated (cardiovascular) anomalies, treatment, postoperative complications and follow-up were also recorded.

The vascular rings in our study were classified according to Klinkhamer and Stewart $(3,4)$ as follows (Fig. 1):

1. Double aortic arch: both patent arches form the ring. 2. Right aortic arch with persistent left ligament: the left arch has obliterated and a right arch with a left ligament forms the ring.

3. Kommerell diverticulum: the ring is formed by a remnant of a incompletely regressed left or right arch, from which the left or right subclavian artery originates, respectively. The ring is completed by the fibrous remnant of this arch.

4. Aberrant right subclavian artery: a partial ring is formed by a persistent seventh intersegmental artery, attached to the descending aorta forming an aberrant right subclavian artery, which has a retro-oesophageal position.

5. Pulmonary sling: the sling is formed by an anomalous left pulmonary artery which originates from the right pulmonary artery, crosses the main stem bronchus and courses between trachea and oesophagus to the left lung.

\section{Results}

\section{Clinical presentation}

Data for 14 boys and 24 girls were studied. The type of vascular ring, age at onset of symptoms, diagnosis and surgery are shown in Table 1. Four patients (11\%) were not operated. All four had an aberrant right subclavian artery; three were asymptomatic and in one the symptoms were unspecific. The presenting symptoms are shown in Table 2. All patients with a double aortic arch or pulmonary sling presented with respiratory symptoms. In both groups one patient had additional complaints of dysphagia. Two patients with a pulmonary sling presented with severe tracheal stenosis requiring tracheal intubation. A Kommerell diverticulum was symptomatic in $6 / 8$ cases $(75 \%)$ and presented predominantly with respiratory complaints, although one patient experienced only dysphagia. An aberrant right subclavian artery caused symptoms in 9/15 (60\%), dysphagia being the most frequent symptom $7 / 15$ $(47 \%)$. A right aortic arch with ligament presented with symptoms in $2 / 4$ patients $(50 \%)$, in both these were respiratory complaints. The median delay between the onset of symptoms and the diagnosis of a vascular ring was 5 mo (range 1-84 mo) in symptomatic patients

Table 1. Anatomical variations in vascular rings, median age at onset of symptoms, at diagnosis and at surgery.

\begin{tabular}{|c|c|c|c|c|c|}
\hline Type of vascular ring & $n(\%)$ & No symptoms & $\begin{array}{l}\text { Median age at first } \\
\text { symptoms }\end{array}$ & $\begin{array}{l}\text { Median age at } \\
\text { diagnosis }\end{array}$ & Median age at surgery \\
\hline 1. Double aortic arch & $7(18 \%)$ & - & Birth (birth - 1d) & $4 \mathrm{mo}(1 \mathrm{~d}-1 \mathrm{y})$ & $4 \mathrm{mo}(2 \mathrm{mo}-1 \mathrm{y})$ \\
\hline 2. $\mathrm{R}$ aortic arch. $\mathrm{L}$ ligament & $4(11 \%)$ & 2 & birth & $1 \mathrm{mo}(3 \mathrm{~d}-5 \mathrm{mo})$ & $1,5 \mathrm{mo}(3 \mathrm{~d}-5 \mathrm{mo})$ \\
\hline 3. Kommerell diverticulum & $8(21 \%)$ & 2 & 2 days (birth -3 mo) & $3.5 \mathrm{mo}(2 \mathrm{wk}-7 \mathrm{y})$ & $4 \mathrm{mo}(1 \mathrm{mo}-7.8 \mathrm{y})$ \\
\hline 4. Aberrant right subclavian artery & $15(39 \%)$ & 6 & Birth (birth - 1 y) & $4.5 \mathrm{mo}$ (birth $-9.3 \mathrm{y})$ & $9.5 \mathrm{mo}(1 \mathrm{mo}-9 \mathrm{y})$ \\
\hline 5. Pulmonary sling & $4(11 \%)$ & - & Birth (birth -3 mo) & $3.5 \mathrm{mo}(2-4 \mathrm{mo})$ & $3.5 \mathrm{mo}(2-4 \mathrm{mo})$ \\
\hline Total & $38(100 \%)$ & $10(26 \%)$ & $28(74 \%)$ & $38(100 \%)$ & $34(89 \%) *$ \\
\hline
\end{tabular}

* 4/38 patients were not surgically treated. All had an aberrant right subclavian artery. Three were entirely free of symptoms, in one there were nonspecific mild symptoms. 
Table 2. Distribution of symptoms.

\begin{tabular}{|c|c|c|c|c|c|c|c|c|}
\hline Type of vascular ring & $n$ & No symptoms & Wheezing & Stridor & Dyspnoea & Cough & $\begin{array}{c}\text { Recurrent } \\
\text { RTI }\end{array}$ & Dysphagia \\
\hline 1. Double aortic arch & 7 & - & 6 & 7 & 7 & 5 & 5 & 1 \\
\hline 2. $\mathrm{R}$ aortic arch. L ligament & 4 & 2 & 2 & 1 & 1 & 1 & - & - \\
\hline 3. Kommerell diverticulum & 8 & 2 & 5 & 5 & 3 & 4 & 4 & 3 \\
\hline 4. Aberrant right subclavian artery & 15 & 6 & 3 & 2 & 2 & 2 & 1 & 7 \\
\hline 5. Pulmonary sling & 4 & - & 4 & 4 & 4 & 1 & 2 & 1 \\
\hline Total & 38 & $10(26 \%)$ & $20(53 \%)$ & $19(50 \%)$ & $17(45 \%)$ & $13(34 \%)$ & $12(32 \%)$ & $12(32 \%)$ \\
\hline
\end{tabular}

Table 3. Congenital anomalies.

\begin{tabular}{|c|c|c|c|c|c|}
\hline Congenital anomaly & 1. Double aortic arch & $\begin{array}{l}\text { 2. } \mathrm{R} \text { aortic arch. } \\
\mathrm{L} \text { ligament }\end{array}$ & $\begin{array}{l}\text { 3. Kommerell } \\
\text { diverticulum }\end{array}$ & $\begin{array}{l}\text { 4. Aberrant right } \\
\text { subclavian artery }\end{array}$ & 5. Pulmonary sling \\
\hline ASD & 1 & - & 2 & 2 & - \\
\hline VSD & - & - & 2 & 2 & 1 \\
\hline $\mathrm{TGA}+\mathrm{VSD}$ & - & 1 & 1 & - & - \\
\hline Fallot & - & 2 & 1 & 1 & - \\
\hline $\mathrm{CoA}$ & - & - & - & 5 & - \\
\hline $\mathrm{PA}+\mathrm{VSD}$ & - & - & - & 1 & - \\
\hline PDA & - & 1 & - & 1 & - \\
\hline Non-cardiac anomalies & - & 1 & 1 & 4 & - \\
\hline Total & 1 & 5 & 7 & 16 & 1 \\
\hline
\end{tabular}

ASD: atrial septal defect, VSD: ventricular septal defect, TGA: transposition of great arteries, T4F: tetralogy of Fallot, CoA: coarctation of aorta, PA: pulmonary atresia, PDA: patent ductus arteriosus.

Table 4. Diagnostic procedures.

\begin{tabular}{|c|c|c|c|c|c|c|c|}
\hline Type of vascular ring & $n$ & $\begin{array}{l}\text { Chest X-ray } \\
\text { Tracheal } \\
\text { compression }\end{array}$ & $\begin{array}{l}\text { ECHO } \\
\text { Vascular } \\
\text { anomaly }\end{array}$ & $\begin{array}{c}\text { Oesophagography } \\
\text { Oesophageal } \\
\text { compression }\end{array}$ & $\begin{array}{l}\text { Angiography } \\
\text { Vascular } \\
\text { anomaly }\end{array}$ & $\begin{array}{l}\text { Bronchoscopy } \\
\text { Malacia/pulsatile } \\
\text { impression }\end{array}$ & $\begin{array}{c}\text { CT } \\
\text { Vascular } \\
\text { anomaly }\end{array}$ \\
\hline 1. Double aortic arch & 7 & $4 / 7$ & $3 / 6$ & $7 / 7$ & $7 / 7$ & $5 / 5$ & $1 / 2$ \\
\hline 2. $\mathrm{R}$ aortic arch. $\mathrm{L}$ ligament & 4 & $2 / 4$ & $0 / 4$ & $2 / 2$ & $4 / 4$ & $1 / 1$ & \\
\hline 3. Kommerell diverticulum & 8 & $3 / 8$ & $1 / 8$ & $6 / 7$ & $8 / 8$ & $5 / 5$ & \\
\hline 4. Aberrant right subclavian artery & 15 & $0 / 15$ & $2 / 14$ & $9 / 9$ & $12 / 13$ & $3 / 3$ & \\
\hline 5. Pulmonary sling & 4 & $1 / 4$ & $1 / 4$ & $0 / 2$ & $3 / 3$ & $4 / 4$ & $1 / 1$ \\
\hline Total & 38 & $10 / 38$ & $7 / 36$ & $24 / 27$ & $34 / 35$ & $18 / 18$ & $2 / 3$ \\
\hline
\end{tabular}

without associated anomalies. The median delay was longest in patients with an aberrant right subclavian artery $(9 \mathrm{mo})$ and in patients with a Kommerell diverticulum $(57 \mathrm{mo})$. The shortest delay occurred in patients with a pulmonary sling $(1 \mathrm{mo})$. Ten patients (26\%) were asymptomatic. The vascular ring in these patients was diagnosed in association with other anomalies. Associated anomalies were found in 22/38 patients (53\%); many patients had more than one associated anomaly. In total, 30 associated anomalies were found, of which the majority were associated cardiovascular anomalies $24 / 30(80 \%)$, as shown in Table 3.

\section{Diagnostic procedures}

The diagnostic procedures performed on the patients are shown in Table 4. A chest X-ray was obtained in all patients. In 10/38 (26\%) it showed tracheal compression. Echocardiography was performed in 36 patients.
In $7 / 36(19 \%)$ it showed a malformation of the aortic arch, but the precise type of vascular ring could not be identified. Echocardiographically a pulmonary sling was missed in 3 out of 4 patients.

An oesophagography was performed in 27 patients. In 11 patients this diagnostic procedure was not performed because diagnosis of a vascular ring was already established by angiography or during surgery. In two of these patients, with a pulmonary sling, severe tracheal compression was diagnosed by bronchoscopy and severe respiratory insufficiency prohibited further diagnostic evaluation before surgery. Oesophagography showed no compression of the oesophagus in three patients; two of these were later diagnosed with a pulmonary sling and the other with an asymptomatic Kommerell diverticulum.

Biplane angiography was performed in 35 patients. No angiography was performed in three patients. In two patients the vascular ring was diagnosed during surgery for another congenital heart disease. In the third patient 
a pulmonary sling was identified during operation for severe tracheal stenosis, that was diagnosed by bronchoscopy. In 34/35 (97\%) biplane angiography showed the exact anatomy of the vascular ring. In one asymptomatic patient an aberrant right subclavian artery was missed. This patient had a coarctation and was operated at the age of $9.3 \mathrm{y}$. During this procedure the aberrant right subclavian artery was identified and ligated. In retrospect the aberrant artery could be identified on the preoperative angiography.

Bronchoscopy was not routinely performed in patients suspected of a vascular ring. All 18/18 (100\%) bronchoscopic exams showed abnormalities: tracheal stenosis, tracheal malacia or an abnormal pulsatile impression. In three patients, two with a double aortic arch and one with a pulmonary sling, a CT scan was obtained. In two patients the vascular anomaly was visualized (double aortic arch and pulmonary sling), in the other a double aortic arch was initially missed.

\section{Surgical management}

A total of 34 patients underwent surgical repair (or ligation) of the vascular ring through a lateral thoracotomy in $24(70 \%)$ and a median sternotomy in 10 (29\%) patients depending on the type of anomaly and associated lesions. Repair of the vascular ring was performed in 27/28 (96\%) patients with symptoms due to a vascular ring and in $7 / 10(70 \%)$ without symptoms. The majority of vascular rings $26 / 34 \quad(76 \%)$ was surgically corrected during the first year of life. The group of patients without symptoms was primarily operated for associated cardiovascular anomalies. In $7 / 10$ patients the vascular ring was corrected because of the risk of possible tracheal and/or oesophageal compression later in life. In the other three patients, in whom the vascular ring consisted of an aberrant right subclavian artery, the vascular ring was left untouched.

\section{Postoperative complications and long-term follow-up}

Follow-up ranged from 1 mo to $12.6 \mathrm{y}$ (median $2.6 \mathrm{y}$ ). There was no intraoperative mortality. Three patients died within $30 \mathrm{~d}$ of surgery $(4 \mathrm{~d}, 13 \mathrm{~d}$ and $29 \mathrm{~d}$, respectively) and another three patients within 4, 7 and 20 mo. In 5/6 patients, mortality was directly related to tracheal stenosis or malacia. In three of these, severe tracheal stenosis was coexistent to a pulmonary sling. Of the remaining patients who underwent surgery because of symptoms $(n=21), 9 \quad(43 \%)$ showed immediate relief of symptoms after surgery and 12 (57\%) experienced relief of symptoms within $4 \mathrm{y}$ following operation. During follow-up the most consistent respiratory symptom was inspiratory stridor due to tracheal malacia. Re-implantation of an aberrant right subclavian artery in two patients was complicated by right-sided transient paresis of the diaphragm and a right-sided transient Horner syndrome.

\section{Discussion}

During foetal life the branchial arch system provides six pairs of primitive aortic arches that develop into the aortic arch and its branches, as well as the pulmonary system. Vascular rings can be explained by abnormal regression of the primitive branchial system and may result in compression of the trachea, oesophagus or both $(1-3,12,13)$. Usually, symptomatic vascular rings are diagnosed in early life, but an important delay between the first presentation of symptoms and the time of diagnosis may exist. The delay in symptomatic patients without associated anomalies in our study ranged from 1 to $84 \mathrm{mo}$. The longest median delay occurred in case of an aberrant right subclavian artery $(9 \mathrm{mo})$ or a Kommerell diverticulum $(57 \mathrm{mo})$ without associated anomalies. In most patients symptoms were already present in the neonatal period. In our study $87 \%$ of the vascular rings was diagnosed during the first year of life. We found that $74 \%$ of the vascular rings presented with symptoms, with wheezing (53\%) and inspiratory stridor $(50 \%)$ as main complaints. Although inspiratory stridor is a classic sign for intrathoracic obstruction, it was not always clearly present. In a few patients with a right aortic arch there was no sign of inspiratory stridor. In cases of an aberrant right subclavian artery the main complaint was dysphagia. Inspiratory stridor, wheezing and dyspnoea are prominent in cases of vascular ring, but also other respiratory symptoms, such as recurrent RTI and cough, may be associated with a vascular ring. Respiratory symptoms are common during infancy, however the presence of these symptoms, during the neonatal period and their persistence should alert the paediatrician to the possible existence of a vascular ring.

In our study we found associated cardiovascular anomalies in $63 \%$ of cases. The distribution of these associated cardiovascular anomalies varies with different vascular rings $(9,10,14-16)$. In cases of aberrant right subclavian artery we found a high number of aortic coarctations.

According to the literature, various types of vascular rings can be suspected on their characteristic appearance on a chest X-ray $(9,11,14,17-19)$. In our study, the value of the chest X-ray was low (26\% showed tracheal impression on the X-ray). A right-sided aortic arch and signs of severe tracheal obstruction (hyperinflation, atelectasis and tracheal compression) are findings on a chest X-ray that should alert the paediatrician on the possibility of a vascular ring.

It is stated that echocardiography is a useful complementary examination that may facilitate optimal intraoperative management by clarifying the relevant anatomy preoperatively as well as excluding other cardiac anomalies $(11,20,21)$. In our study echocardiography confirmed the presence of a vascular ring in only $19.5 \%$ of subjects. This may be explained by the fact that in our study echocardiography did not always focus 
on vascular rings. Differences in techniques (colour Doppler) between 1981 and 1997 may be another explanation for the low outcome of echocardiography in our study. In our opinion echocardiography is unable to provide a reliable diagnosis concerning the presence of a vascular ring, however it is essential to rule out associated cardiac anomalies. When a vascular ring is suspected, non-invasive radiological diagnosis can be established by oesophagography $(12,22)$. In $89 \%$ of our cases an oesophagography showed compression of the trachea, oesophagus or both. Oesophagography may demonstrate posterior compression of the oesophagus in all vascular rings except a pulmonary sling $(7,9,23$, 24). In this situation an anterior indentation of the oesophagus and an increased space between oesophagus and trachea at the same level occurs. Nevertheless, the exact anatomy of a vascular ring cannot be delineated by oesophagography. This contrasts biplane angiography, which defines the exact vascular structures $(7,10,25)$. In our study, biplane angiography confirmed the diagnosis in $97 \%$ of cases. However, angiography has several drawbacks: it is an invasive procedure and in a paediatric population heart catheterization may often require hospital admission and general anaesthesia. In our study three CT scans were obtained. In two cases the CT scan confirmed a vascular ring (double aortic arch and pulmonary sling), in the other case a double aortic arch was initially missed. No MRI studies were performed in our series. Although biplane angiography always has been considered the gold standard in the determination of the exact anatomy of vascular rings, increasing evidence is becoming available that CT scan or MRI may replace this role $(9,11,20,25-27)$. These techniques provide anatomical details of non-vascular structures, such as trachea and oesophagus and their relation with the vascular anatomy (28). In contrast to biplane angiography, these techniques are non-invasive and do not necessarily require hospital admission, although it has to be kept in mind that sedation or anaesthesia is often required in infants and young children (27). Bronchoscopic examination is used in the diagnosis of upper airway problems and usually confirms the location and severity of extrinsic airway obstruction; this procedure again can not define the anatomy of a vascular ring. Bronchoscopy can cause tracheal oedema, which may worsen tracheal obstruction. Nevertheless, bronchoscopy may provide a basis for comparison of airway patency before and after surgery. In our study diagnostic bronchoscopy was performed in 18 patients and showed an abnormal pulsatile impression with or without tracheal malacia in all patients. Tracheal abnormalities were present in all the types of vascular rings.

Complete identification, dissection and mobilization of the relevant vascular structures, as well as identification of the trachea and oesophagus, is necessary for adequate surgery of the vascular ring. Vascular rings can be corrected during cardiac surgery through a median sternotomy (29). All vascular rings that cause symptoms should be corrected. In the case of an aberrant right subclavian artery, which is symptom free in most of the cases, there is no strict indication for operation. In the case of dysphagia there is an indication for operation. In our study, in seven patients an aberrant right subclavian artery was corrected during surgery for another cardiac anomaly. Exact knowledge of the path of the phrenical nerve is essential in order to avoid damage. In our study transient paresis of the phrenical nerve was present in two cases, both after division and re-implantation of an aberrant right subclavian artery. In cases of a Kommerell diverticulum it is suggested not only to divide and ligate the vascular ring, but also completely to excise the diverticulum. When left in situ this diverticulum may become aneurysmatic later in life and may lead to symptoms of oesophageal compression $(8,24)$. It should be acknowledged that tracheal malacia or stenosis frequently complicates vascular rings. Pulmonary slings especially are known to be associated with severe, life-threatening tracheal stenosis, that requires tracheal surgery and that may seriously complicate outcome $(30,31)$. In our series mortality was due to tracheal malacia or stenosis in $5 / 6$ patients. After surgery there is no immediate recuperation of the tracheal deformity, thus avoidance of tracheal manipulation is essential. Respiratory insufficiency after surgery can occur due to tracheal oedema as a result of manipulation during operation (14).

New surgical techniques, such as thoracoscopy, seem promising, but need further development (22). In general the results of surgical treatment are good. In our study $43 \%$ of the patients with symptomatic vascular rings experienced immediate relief of symptoms after surgery. Another 57\% were symptom free within $4 \mathrm{y}$. Operative risks are relatively small.

\section{Limitations}

This is a retrospective study and, consequently, it has certain limitations. Not all diagnostic procedures were performed in all patients, therefore it is not possible to demonstrate the sensitivity or specificity of the different diagnostic procedures. The population consists of a selected patient group from a tertiary reference centre. In our series of patients with vascular rings, associated cardiovascular anomalies may be a confounding factor, with respect to the respiratory complaints. However, the patients without associated cardiac anomalies showed a similar pattern of complaints.

We conclude that prolonged or recurrent respiratory complaints or dysphagia in infancy or childhood should alert the paediatrician to the possibility of a vascular ring. Associated cardiac anomalies may be present in up to $63 \%$ of the patients with a vascular ring. When a vascular ring is suspected, radiological diagnosis can be established by oesophagography. Biplane angiography 
provides exact vascular anatomy, however CT scan or MRI may replace angiography in this respect. Early surgical treatment of symptomatic vascular rings allows normal growth of the trachea and will give relief of symptoms.

\section{References}

1. Gross RF. Surgical relief for tracheal obstruction from a vascular ring. N Engl J Med 1945; 233: 586-90

2. Edwards JE. Anomalies of the derivates of the aortic arch system. Med Clin North Am 1948; 41: 925-41

3. Stewart JR. An atlas of vascular rings and related malformations of the aortic system. Springfield: Charles C Thomas, 1964

4. Klinkhamer AC. Esophagography in anomalies of the aortic arch system. Baltimore: Williams \& Wilkins, 1969

5. Gasul BM, Arcilla RA, Lev M. Heart disease in children: diagnosis and treatment. Philadelphia: Lippincott, 1966: 2

6. Keith JD, Rowe RD, Vlad P. Heart disease in infancy and childhood. 1967; 2nd edn

7. Backer CL, Ilbawi MN, Idriss FS, DeLeon SY. Vascular anomalies causing tracheoesophageal compression. Review of experience in children. J Thorac Cardiovasc Surg 1989; 97: 72531

8. Chun K, Colombani PM, Dudgeon DL, Haller JA Jr. Diagnosis and management of congenital vascular rings: a 22-year experience. Ann Thorac Surg 1992; 53: 597-602; discussion 602-3

9. Mahoney EB, Manning JA. Congenital abnormalities of the aortic arch. Surg 1964; 55: 1-14

10. van Son JA, Julsrud PR, Hagler DJ, et al. Surgical treatment of vascular rings: the Mayo Clinic experience. Mayo Clin Proc 1993; 68: 1056-63

11. van Son JA, Julsrud PR, Hagler DJ, et al. Imaging strategies for vascular rings. Ann Thorac Surg 1994; 57: 604-10

12. Roesler M, De Leval M, Chrispin A, Stark J. Surgical management of vascular ring. Ann Surg 1983; 197: 139-46

13. Tucker BL, Meyer BW, Lindesmith GG, Stiles QR, Jones JC. Congenital aortic vascular ring. Arch Surg 1969; 99: 521-3

14. Nikaidoh H, Riker WL, Idriss FS. Surgical management of "vascular rings". Arch Surg 1972; 105: 327-33

15. Rivilla F, Utrilla JG, Alvarez F. Surgical management and follow-up of vascular rings. Z Kinderchir 1989; 44: 199-202

16. Kocis KC, Midgley FM, Ruckman RN. Aortic arch complex anomalies: 20 year experience with symptoms, diagnosis, associated cardiac defects, and surgical repair. Pediatr Cardiol 1997; 18: 127-32
17. van Aalderen WCM, Hoekstra MO, Hess J, Knol K. Respiratory infections and vascular rings. Acta Pediatr Scand 1990; 79: 47780

18. Neuhauser EBD. The roentgen diagnosis of double aortic arch and other anomalies of the great vessels. Am J Roentgenol 1946; 56: $1-12$

19. Wolf BHM, Aronson DC, Verboom AJ, Losekoot G. Adembenemende hart-en vaataandoeningen op de kinderleeftijd. Tijdschr Kindergeneesk 1986: 84-9

20. Beekman RP, Beek FJ, Hazekamp MG, Meijboom EJ. The value of MRI in diagnosing vascular abnormalities causing stridor. Eur J Pediatr 1997; 156: 516-20

21. Lillehei CW, Colan S. Echocardiography in the preoperative evaluation of vascular rings. J Pediatr Surg 1992; 27: 1118-20; discussion 1120-1

22. Burke RP, Rosenfeld HM, Wernovsky G, Jonas RA. Videoassisted thoracoscopic vascular ring division in infants and children. J Am Coll Cardiol 1995; 25: 943-7

23. Brown DL, Chapman WC, Edwards WH, Coltharp WH, Stoney WS. Dysphagia lusoria: aberrant right subclavian artery with a Kommerell's diverticulum. Am Surg 1993; 59: 582-6

24. Han MT, Hall DG, Manche A, Rittenhouse EA. Double aortic arch causing tracheoesophageal compression. Am J Surg 1993; 165: 628-31

25. Azarow KS, Pearl RH, Hoffman MA, Zurcher R, Edwards FH, Cohen AJ. Vascular ring: does magnetic resonance imaging replace angiography? Ann Thorac Surg 1992; 53: 882-5

26. van Son JA, Starr A. Demonstration of vascular ring anatomy with ultrafast computed tomography. Thorac Cardiovasc Surg 1995; 43: 120-1

27. Task force report. The clinical role of magnetic resonance in cardiovascular disease. Eur Heart J 1998; 19: 19-39

28. Beekman RP, Hazekamp MG, Sobotka MA, Meijboom EJ, de Roos A, Staalman CR, et al. A new diagnostic approach to vascular rings and pulmonary slings: the role of MRI. Magn Reson Imaging 1998; 16: 137-45

29. Bogers AJ, Cromme-Dijkhuis AH, Bos E. Conversion of aberrant right subclavian artery into right subclavian artery in one-stage neonatal repair of aortic arch anomalies and intracardiac defects. Eur J Cardiothorac Surg 1992; 6: 514-6

30. Backer CL, Mavroudis C, Dunham ME, Holinger LD. Repair of tracheal stenosis with free tracheal autograft. J Thorac Cardiovasc Surg 1998; 115: 869-74

31. Kessler RM, Wernly JA, Katz RW, Berman W Jr. Pulmonary artery sling with severe tracheobronchial stenosis: repair in infancy by tracheal resection and pulmonary artery reimplantation. J Card Surg 1992; 7: 5-8

Received Oct. 26, 1998; revision received Apr. 6, 1999; accepted Apr. 15, 1999 